\title{
THE INFLUENCE OF DISTANCE BETWEEN THE FLOATS OF CATAMARAN HULL
}

\author{
Alin Pohilca \\ "Dunarea de Jos" University of Galati, \\ Faculty of Naval Architecture, Galati, Domneasca \\ Street, No. 47, 800008, Romania, \\ E-mail: alin.pohilca@glo-marine.com

\section{Liviu Galateanu} \\ "Dunarea de Jos" University of Galati, \\ Faculty of Naval Architecture, Galati, Domneasca \\ Street, No. 47, 800008, Romania, \\ E-mail: liviu.galatanu@glo-marine.com
}

\author{
Matei Cosmin Baciu \\ "Dunarea de Jos" University of Galati, \\ Faculty of Naval Architecture, Galati, Domneasca \\ Street, No. 47, 800008, Romania, \\ E-mail: baciumateicosmin@yahoo.ro

\section{Costel Iulian Mocanu} \\ "Dunarea de Jos" University of Galati, \\ Faculty of Naval Architecture, Galati, Domneasca \\ Street, No. 47, 800008, Romania, \\ E-mail: costel.mocanu@ugal.ro
}

\begin{abstract}
This study presents the influence of the distance between the floats of catamaran for ship calm water resistance. As we know, a catamaran is composed by 2 floats, each float having its own wave systems in calm water. The distance between these floats influences the phenomena that appear due to the composition of the wave systems. The low value of the calm water resistance force is provided by the optimum distance of the floats. In this study, there will be used 3 different distances of the floats for the main speed of the ship. To estimate the ship resistance there will be used RANS equations which provide a good fluid flow in turbulent models.
\end{abstract}

Keywords: ship hydrodynamic resistance, calm water resistance, hull optimization.

\section{INTRODUCTION}

This study's scope is to optimize a high speed multi hull ship to reduce the calm water resistance.

The first issue that we consider is that the operational zone is on the Danube River and the Danube Delta Biosphere reservation, strictly protected against noise and pollution. Also, we consider that the operational regime of the ship is $90 \%$ in calm water because, in the worst cases, the wave is not more than $0.5 \mathrm{~m}$ on the Danube River during a one year period.

To respect these requirements in parallel with the study of hull shape, it is necessary to also study the position of the floats against centre line. This distance can have an important influence on water resistance value and also on the high waves simulation.
The analysis was conducted for a passenger ship with two floats (catamaran type) and $21 \mathrm{~m}$ in length. The ship's speed is 21.4 knots $(11 \mathrm{~m} / \mathrm{s})$ at 0.8 Froude number. The high Froude number of the ship places it in semi-displacement regime. The catamaran is presented in Fig. 1.

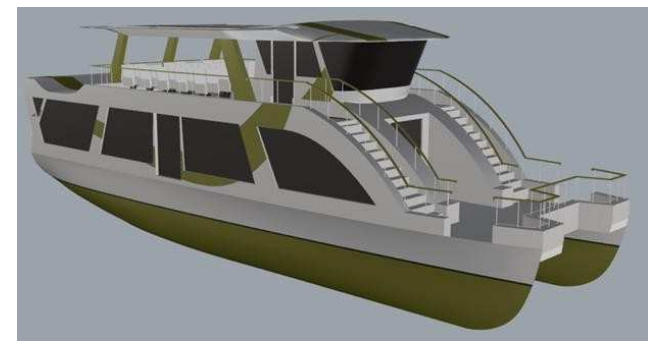

Fig. 1. Passenger ship 


\section{CONTENT}

The route of the passenger ship is from Galati to Tulcea for a $85.3 \mathrm{~nm}$ distance which is presented in Fig.2.

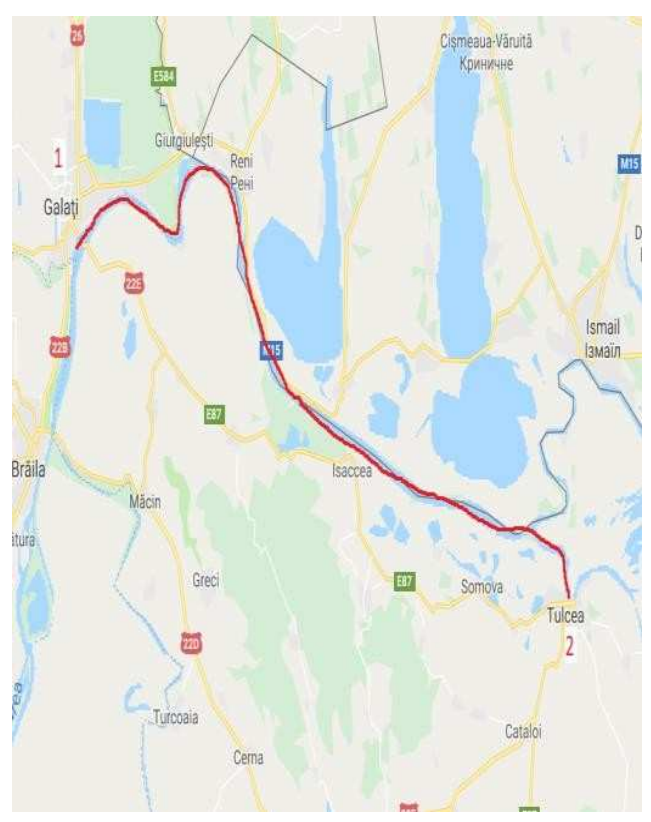

Fig. 2. The route of the ship

Due to economic factors and the pollution constraints in the operational zone, an efficient ship is a ship that arrives in a short time at the harbour with a low consumption and pollution level [1,2].

The catamaran ships are characterized by a low hydrodynamic resistance in calm water. Hence, the multi hull ship is the best choice due to the navigation area that has waves with a low height and period.

However, a major problem of the multi hull ships is the hydrodynamic interference between the floats. A solution to reduce it is to find an optimal position of the floats for a sailing speed. Numerous variants of the arrangement of floats have been tried so that the interference between them is minimal. Various researchers propose innovative solu- tions that will minimize the influence of the bodies at different speeds of navigation.

The distance considered is presented in Fig.3.

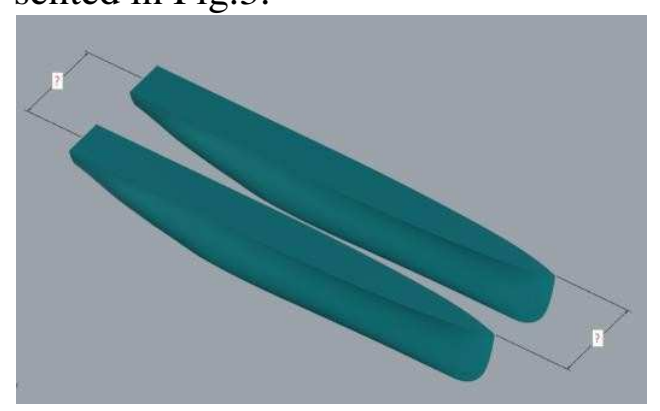

Fig. 3. The distance of the floats

\section{NUMERICAL SIMULATION MODEL}

The mathematical model used for numerical simulations is based on RANS equations and the mathematical model of the fluid flow is SST-Menter [4].

The first statement of the fluid flow simulation is representing by the conservation laws of physics:

-The mass of the fluid particle is conserved;

-Newton's second law which refers to the momentum conservation;

-The first law of thermodynamics which refers to the energy conservation.

The Navier-Stokes equations are frequently used for steady state flow in numerical analysis of the fluids flow because they can be easily described by mathematical algorithms compared to Helmholtz equations or GromekaLamb equations. Also, the Navier-Stokes equations on the 3 directions of the fluid flow indicate equality between the sum of the unitary local and convective inertia forces and the sum of the unitary pressure forces, the unitary mass forces and the unitary viscous forces which represent the unitary external forces that act on the fluid particle. 
The Navier-Stokes equations are enough to describe the laminar fluid flow, but, in order to describe the real fluid flow, we need to add the Reynolds number which gives us the limit between the laminar fluid flow and the turbulent fluid flow. For different kind of the flow we can find the critical Reynolds number which shows us the switching from the flow regime to another one. Thus, Reynolds decomposition is used for numerical analysis and this theory assumes that at every step of time, the velocity $\mathrm{u}$ is not constant, being influenced by a time dependent component $\mathrm{u}^{\prime}(\mathrm{t})$.

For this study was used Numeca: FineMarine software [3]. The grid of the analysis has been iterative realized from the coarse mesh to a fine mesh so as to capture the phenomena on the free surface, as we can see in Fig.4 [6].

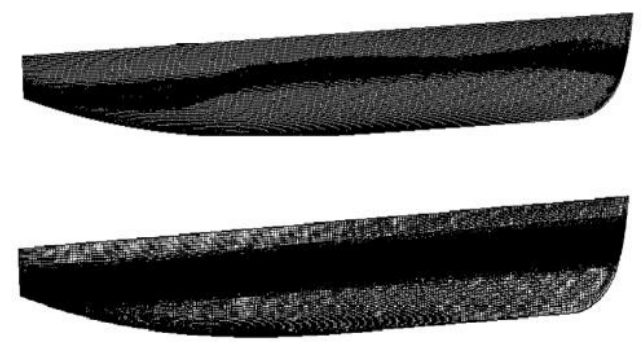

Fig. 4. The grid of the analysis

For the free surface and the hull surface, it has been used a grid that contains 2 million cells with refined area on the Kelvin surface [5].

\section{THE FIRST DISTANCE BETWEEN FLOATS}

In Fig. 5 it is shown the first iteration that has used $4.4 \mathrm{~m}$ distance between the centre line of the floats.

The hydrodynamic resistance value at $11 \mathrm{~m} / \mathrm{s}$ velocity of flow is 34 $\mathrm{kN}$.

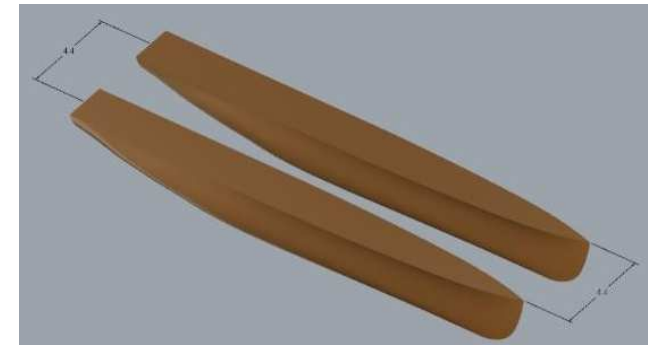

Fig. 5. The distance of the floats

The phenomena that appear on the free surface are illustrated in Fig.6, Fig 7 and Fig. 8. and include the following:

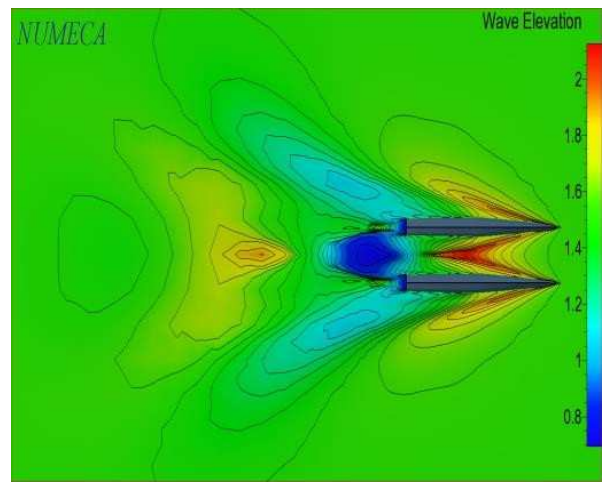

Fig. 6. The fluid flow phenomena

1. Wave crest in the fore-ship area between the floats $-2.2 \mathrm{~m}$ height from the base line of the ship;

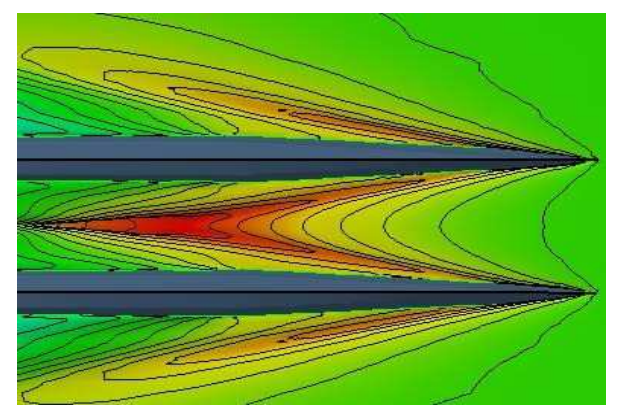

Fig. 7. The grid of the analysis

2. Wave trough in the aft-ship area between the floats $-0.6 \mathrm{~m}$ depth from the free surface. 


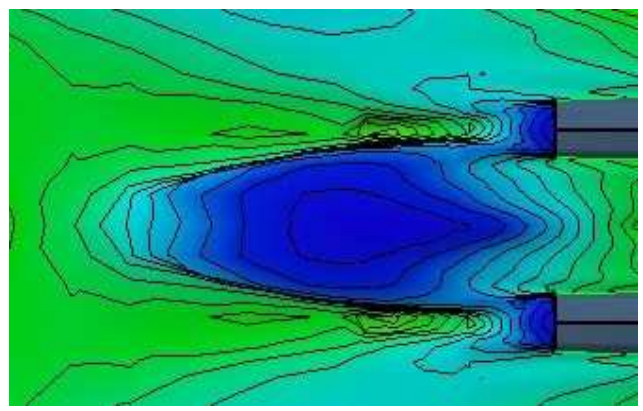

Fig. 8. The wave trough

This step of the study shows the areas of the fluid flow that negatively influence the calm water hydrodynamic resistance.

\section{THE SECOND DISTANCE BETWEEN FLOATS}

For a second iteration it has been used a $4.8 \mathrm{~m}$ distance between the centre line of the floats, as presented in Fig. 9. The hydrodynamic resistance value at $11 \mathrm{~m} / \mathrm{s}$ velocity of flow is $30.5 \mathrm{kN}$.

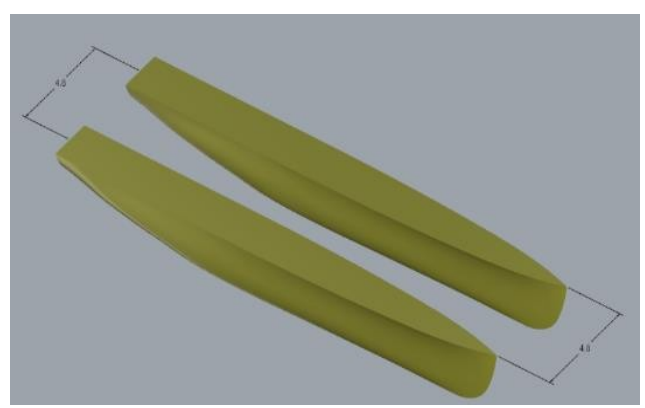

Fig. 9. The distance of the floats

The phenomena that appear on the free surface are the following, presented in Fig.10, Fig. 11 and Fig. 12:

3. Wave crest in the fore-ship area between the floats $-2 \mathrm{~m}$ height from the base line of the ship;

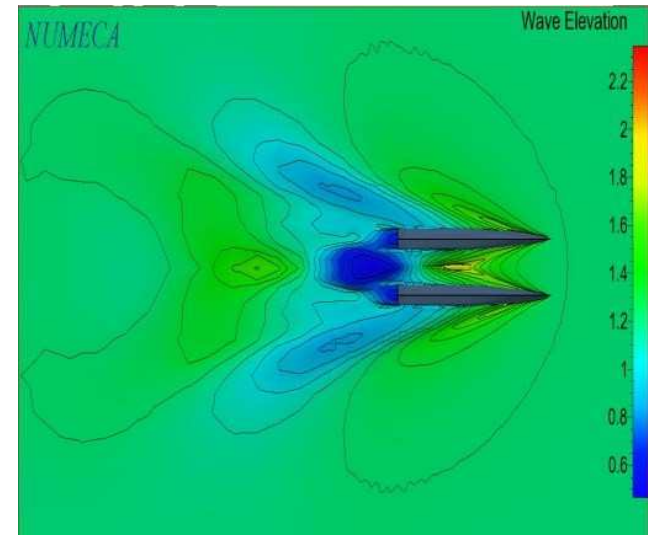

Fig. 10. The fluid flow phenomena

4. Wave trough in the aft-ship area between the floats $-0.8 \mathrm{~m}$ depth from the free surface.

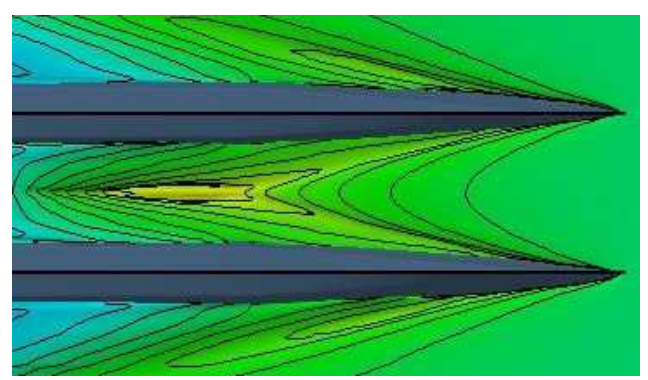

Fig. 11. The wave crest

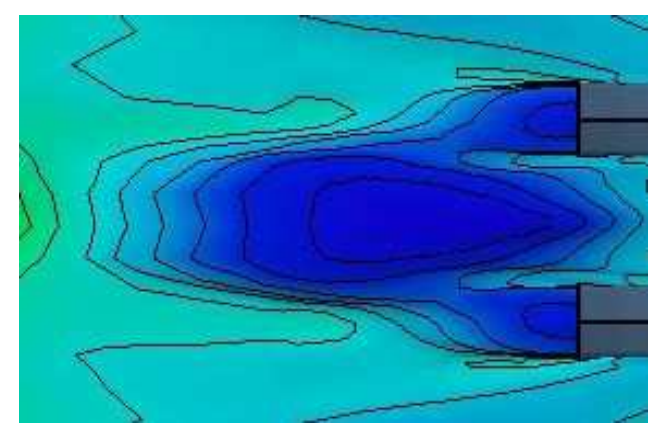

Fig. 12. The wave trough

This step of the study shows that the distance between the floats reduce the wave crest in the fore-ship area and the hydrodynamic resistance. 


\section{THE THIRD DISTANCE BETWEEN FLOATS}

For a second iteration it has been used a $5.1 \mathrm{~m}$ distance between the centre line of the floats, as shown in Fig. 13.

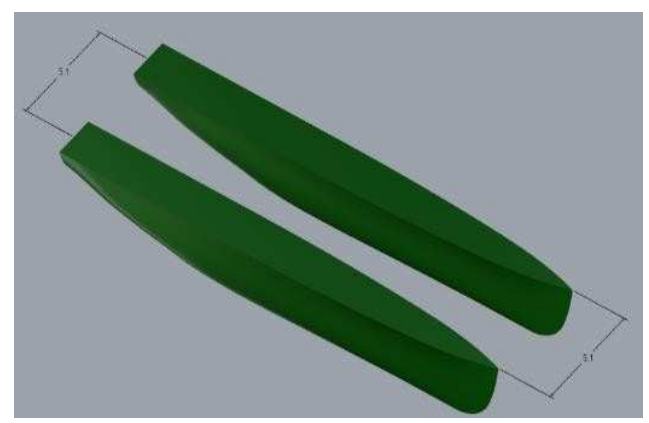

Fig. 13. The distance of the floats

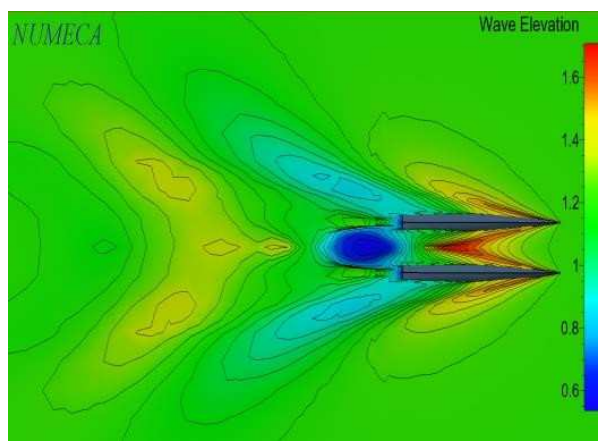

Fig. 14. The fluid flow phenomena

The phenomena that appear on the free surface are the following, illustrated in Fig. 14, Fig. 15 and Fig. 16:

5 . Wave crest in the fore-ship area between the floats $-1.8 \mathrm{~m}$ height from the base line of the ship;

6. Wave trough in the aft-ship area between the floats $-0.8 \mathrm{~m}$ depth from the free surface (Fig. 16).

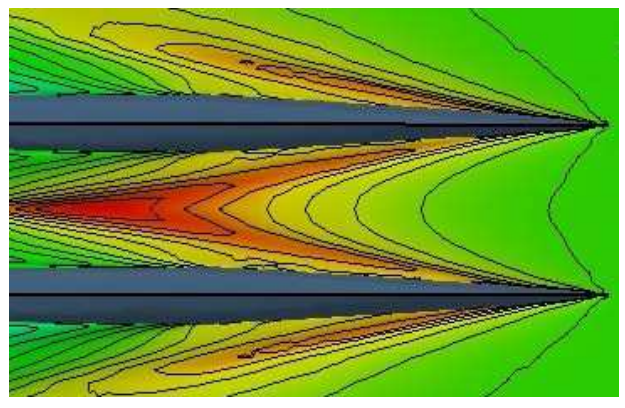

Fig. 15. The wave crest

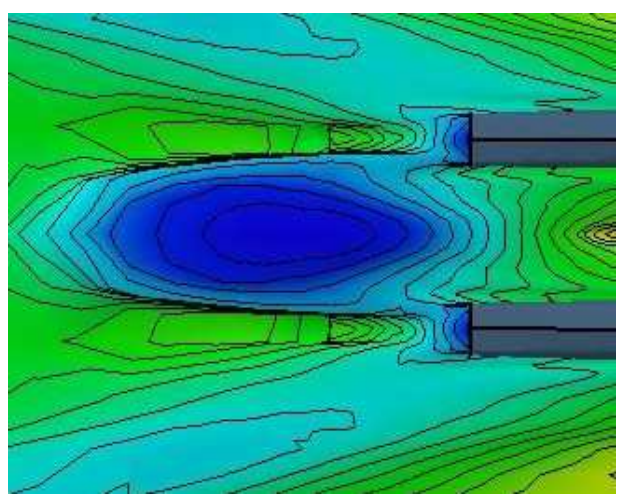

Fig. 16. The wave crest

Table 1. Comparison of different distances of the float

\begin{tabular}{|c|c|}
\hline Distance $[\mathrm{m}]$ & $\mathrm{Rt}[\mathrm{kN}]$ \\
\hline 4.4 & 34 \\
\hline 4.8 & 30.5 \\
\hline 5.1 & 26.3 \\
\hline
\end{tabular}

\section{CONCLUSIONS}

Hence, the calm water ship resistance has been decreased with the increase of the distance between the floats. We can affirm that for this type of shape the increase by $0.4 \mathrm{~m}$ represents the decrease of $4 \mathrm{kN}$ from hydrodynamic resistance, as we can see in Table.1.

\section{Acknowledgements}

The research was supported by the Naval Architecture Faculty from "Dunarea de Jos" University of Galati, which is greatly acknowledged. 


\section{REFERENCES}

[1]. IMO, "International Maritime Organization Rules", MARPOL Annex VI, Chapter 4

[2]. Cofala,J., Amann, M., Heyes, C., Wagner, F., Klimont, Z., Posch , M., Schopp, W., Tarasson, L., Jonson, J.E., Whall, C., Stavrakaki, A., "Analysis of Policy Measures to Reduce Ship Emissions in the Context of the Revision of the National Emissions Ceilings Directive - Final Report", European Com- mission, DG Environment, Unit ENV/C1 Contract No 070501/2005/ 419589 /MAR /C1
[3]. Verseteeg, H.K., Malalasekera, W. "An Introduction to Computational Fluid Dynamics The Finite Method", Second Edition, Pearson Education Limited 1995/2007 United Kingdom

[4]. Ferziger, J.H., Peric, M., "Computational Methods for Fluid Dynamics", $3^{\text {rd }}$ Edition Springer-Verlag Berlin Heidelberg New York 2002

[5]. Chung, T.J., "Computational Fluid Dynamics”, First Edition Cambridge University Press 2002 - United Kingdom,

[6]. ISIS-CFD Centrale Nantes / CNRS, "Numeca Fine Marine Theoretical Manual" 2017

Paper received on July $30^{\text {th }}, 2019$ 